\title{
artículos
}

\section{Fundamentos teóricos y metodológicos de las investigaciones sobre la actividad de las bibliotecas públicas cubanas, estado actual y perspectivas de desarrollo de esas investigaciones}

Emilio Setién ${ }^{1}$

\section{RESUMEN}

Se pre sen tan y eva lúan los re sul ta dos al can za dos por el pro gra ma de in ves ti ga cio nes del sis te ma de las bi blio te cas pú bli cas cu banas has ta 1987. Se ex po nen los fun da men tos teó ri cos que sir ven de base al pro gra ma y sucon cep ción sis té mi ca. Se ex pli cala organización del trabajo científico en el sistema de bibliotecas antes mencionado.

\section{SUMMAR Y}

The resaults obtained by the research programme of cuban public library system up to 1987 are presented and evoluted in this work. The theoretical foundations that con tribute to the progam me and its sys te matic con cep tions are des cribed. The or ga ni zation of scientific work in the Cuban library system is also explained.

\section{INTRODUCCION}

Las in vesti gaciones cien tíficas sobre la actividad de las bibliotecas públicas en Cuba comenzaron a desarrollarse institucionalmente desde 1981, año en que se incorporaron al problema prin ci pal de las cien cias so cia les No. 206, ti tu la do "Líneas fundamentales para el desarrollo del trabajo cultural, a partir del es tu dio de las ne ce si da des de la co mu ni dad", que es tu vo bajola dirección del Ministerio de Cultura. Esas investigaciones son supervisadas por la Academia de Ciencias, en virtud de sus funciones en la dirección de los procesos científicos de la nación. Existen experiencias anteriores a 1981 que crearon las con di ciones para el di seño de las in ves ti gaciones em pren di das en ese año. Ya en 1980 el II Con gre so del Par ti do Co mu nis ta de Cuba se pronunció sobre la ne cesidad del trabajo cien tífi co de esta esfera. ${ }^{2}$

El trabajocientífico de las bibliotecas públicascubanastiene como obje ti vocen tral el perfec cio na mien to de la ac ti vi dad de dichas instituciones. Los resultados de las investigaciones concluidas hasta el presente son, mayormente, aquellos que contribuyen a modificar la práctica de la actividad de las bibliotecas públicas y a implantar métodos para que esas instituciones autorregulen objetivamente su tra ba jo. Así, esos resultados permiten clasificar a las investigaciones antes men cio na das como de ca rác ter apli ca do. No obs tan te, su con- cep ción y de sa rro llo han con du ci do a la pre ci sión y en ri quecimiento teórico de la Bibliotecología en el plano nacional.

Se han realizado principalmente investigaciones aplicadas sobre la formación de fondos, el trabajo con los lectores y la orga ni za ción del trabajo en las biblio te cas. De esas in vestigacio nes apli ca das se han de ri va do tres ti pos de re sul ta dos fundamentales: la iden ti fi ca ción de las ten den cias que se pre sentan en el comportamiento de las esferas antes mencionadas; prin ci pios y mé to dos para la re gu la ción de esas ten den cias; y diseños de estudios concretos que permiten analizar la situación de cada biblioteca en particular.

Con vistas a la regulación de las tendencias que se presentan en la actividad de las bibliotecas públicas, y sobre la base de los resultados de las investigaciones realizadas, la Dirección de Bibliotecas del Ministerio de Cultura — centro de dirección metodológica del sistema- encauza su trabajo hacia la elaboración de proyectos de documentos legales, lineamientos de trabajo, pla nes de ta reas prin ci pa les, nor mas e ins trucciones me to doló gicas, planes de actualización delbibliotecario, diseño de controles estadísticos y de indicadores cuantitativos relativos.

Los mé to dos ela bora dos para la au to rre gu la ción de las bi bliotecas se proponen contribuir a la solución de los problemas exis ten tes, se gún las con di cio nes es pe cífi cas de cada pro vin-

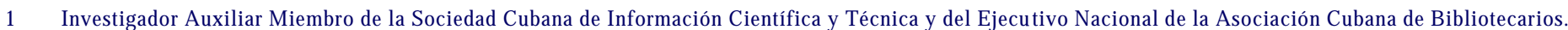

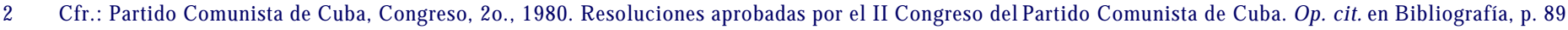


cia, mu ni ci pio o ins ti tu ción, en el mar co de las me di das dic tadas para regular las tendencias que exis ten a ni vel de sis te ma nacio nal, con el fin de fa vo re cer asíla apli ca ción del prin ci pio decen trali za ción y des cen tra li za ción en la direc ción del sis tema de bibliotecas públicas del país.

Los resultados que se alcanzan con la aplicación de esos méto dos cons ti tu yen, ade más, la base de da tos en que se apo ya el centro de dirección metodológica para la elaboración de los lineamiéntos que guían el trabajo de todo el sistema.

\section{LEYES, CATEGORIAS, TEORIAS Y CONCEPTOS PRINCIPALES DE LA BIBLIOTECOLOGIA}

En la actualidad la Bibliotecología es reconocida universalmentecomounadisciplinacien tífica, relativamentein dependiente, que corresponde a la esfera de las ciencias sociales. Exis ten, no obs tan te, dis tin tos cri te rios con res pec to a su conte ni do, a su es truc tu ra, a la po si ción que ocu pa en el con jun to de las cien cias y a las re la cio nes que man tie ne con otras dis ciplinas, especialmente con aquellas que le son contiguas: la Bibliografología, la Informática, la Bibliología.

Sin ne ce si dad de en trar en el aná li sis de las di fe ren cias apunta das, pue de de cir se que las in ves ti ga cio nes de las bi blio te cas públicas cubanas se ba san en la con cep ción de que la Bi bliote colo gía, como dis ci pli na cien tífica, se ocu pa de un fe nómenocaracterístico: la or ga ni za ción y orien ta ción del uso del libro como propiedad social. Esta característica la diferencia de las dis ci pli nas que le son con ti guas, y que se re la cio nan también con el libro (su producción, comercialización y divulgación, y con los servicios de información que se organizan a partir de él), al tiempo que permite identificar las relaciones que se establecen entre la Bibliotecología y esas disciplinas.

En la con cep ción que se ana li za, el li bro se de fi ne como produc to de la cul tu ra ma te rial y de la vida es pi ri tual de la sociedad, históricamente conformado, aún en desarrollo, que fija la in for ma ción se mán ti ca des ti na da a su con ti nua asimilación y transmisión en el tiempo y el espacio. De contenido artístico, literario, científico o práctico, sirve como arma ideológica y política, como medio de educación y de difusión de cualquier información. ${ }^{4}$

Además de mantener relaciones muy estrechas con las disciplinas contiguasmencionadasanteriormente, laBibliotecología se en tre la za con otras cien cias, en tre las que ocu pan lu gares pre do mi nan tes la So ciolo gía, la Psi co lo gía, la Pe da go gía, la Matemática y distintas disciplinas tecnológicas."
La especificidad de la Bibliotecología y las relaciones que man tie ne con otras dis ci pli nas, con ti guas o no, cons ti tu ye una manifestaciónde las tendencias de la cienciacontemporánea a la integración y a la diferenciación.En este trabajo se enfocan, fundamentalmente, los factores que definen la diferenciación de la Bibliotecología, sin obviar algunas consideraciones imprescindibles referentes a su integración con otras ciencias.

La concepción teórica de las investigaciones de las bibliotecas públicas cu ba nas par te de la de fi ni ción de la Biblio te cología como una disciplina particular de las ciencias sociales contemporáneas, relativamente independiente y eminentemente clasista y partidista, que estudia las leyes del desarrollo, las propiedades, el ca rác ter y la es truc tu ra de la actividad bibliotecaria.

La ac ti vi dad bi blio te ca ria es el ob je to de es tu dio de la Bibliotecología, su categoría principal. Por actividad bibliotecaria se entiende a la for ma de co mu ni ca ción so cial, que se basa en el uso del libro como propiedad colectiva, y que promueve ese uso para contribuir a la elevación del nivel ideológico, político, científico y cultural de los lectores; ${ }^{6}$ com prende un con jun to de dis posiciones socia les y es ta tales, así como los proce di mien tos cien tífi cos y prác ti cos relacionados con la organización, administración y trabajo co ti dia no de las bi blio te cas y con la orien ta ción de la lec tura. ${ }^{7}$ Es, en resumen - como ya quedó apuntado-, la actividad que pro pi cia y orien ta el uso del li bro como pro pie dad colec tiva, en be ne fi cio de la so cie dad, a tra vés de un sis te ma de préstamos.

Laactividadbibliotecariase materializaprincipalmente, pero no úni ca men te, en las bi blio te cas. En ella par ti ci pan, ade más de los bibliote carios y los lec to res, los or ga nis mos que tie nen a su car go la di rec ción del de sa rro llo de la so cie dad, así como aquellos que se ocupan de la formación de los bibliotecarios. La efec tivi dad dela ac ti vidad biblio te caria se ma ni fies ta en el alcance social de las bibliotecas.

Comotodadisciplinacientífica, laBibliotecologíaconstituye un sis te ma de le yes, ca te go rías, teo rías, con cep tos y mé to dos de investigación.

La ac ti vi dad biblio te caria, en tan to fe nóme no sociales pecífico, de pen de nece saria mente, y enúl ti mains tan cia, de las condiciones políticas, económicas y culturales que prevalencen en la so cie dad. En esas con di cio nes de sa rro llan su ac ción los elementos creadores y difusores del libro (autores, editores, sistema poligráfico, distribuidores - comerciales o no-) y los ele men tos que mo ti van y for man las ha bi li da des y el há bito de lectura (vida familiar, sistema de educación, actividad

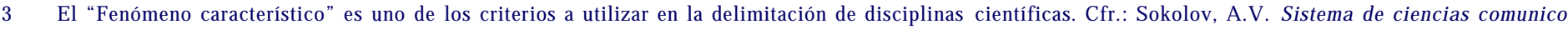
informativas. Op. cit. en Bibliografía, p.5.

Cfr.: Shamurin, E.I. Slovar' Knigovedcheskihk terminov. Op. cit. en Bibliografía, p. 119. Gran Enciclopedia Soviética. Op. cit. en Bibliografía, t.12, p. 335

Cfr.: Chubarian, O.S. Bibliotecología general. Op. cit. en Bibliografía, p. 48-56

Ibid., p. 9

Cfr.: Academia de Ciencias de Cuba. Diccionario de términos de Informática; español, ruso, inglés. Op. cit. en Bibliografía, t. 2, p. 12 
laboral, ac ti vi dad de or ga ni za ciones po líticas y sociales, ac ti vi dad de los me dios de di fu sión ma si va, sis te ma de ins ti tu ciones culturales).

El juego mutuo y complejo de las acciones y reacciones de esos ele men tos con for ma los cri te rios en que se apo yan los biblio te ca rios para la cons truc ción de los fon dos de las bi blio tecas (fondo bibliotecario), y los criterios en que se apo yan los lec to res para es co ger lo que leen. En la prác ti ca es tos cri te rios no son idén ti cos, se con tra po nen (po si bi li da des de los bi bliotecarios - necesidades de los lectores expresadas en sus demandas más o menos precisas). La búsqueda de la correspondencia activa entre el fondo bibliotecario y la demanda de los lectores es, por tanto, el principio fundamental paraeldesarrollo dela actividadbibliotecaria. Correspondenciaactiva, pues to que si bien la de man da de los lec tores incide en la conformación de criterios sobre la com po si ción de los fon dos, la ac ción de los bi blio te carios, sobre la base de determinados principios de formación de fondos y de trabajo con los lectores, contribuye a precisar y a orientar esa demanda para satisfacerla, o para modificarla, tanto desde el punto de vista cuantitativo como cualitativo, con el fin de lograr la elevación del volumen de la lectura, de su variedad y calidad.

La de fi ni ción de ac ti vi dad bi blio te ca ria, la ex pli ca ción de los ne xos que con ca rác ter de ley se es ta ble cen en tre las con di ciones políticas, económicas y culturales y esa actividad, así comola for mu la ción del prin ci pio fun da men tal de co rres pondencia entre el fondo bibliotecario y la demanda de los lectores, permitenidentificar diver sos conceptos generales ocategorías principales de la Bibliotecología. Algunas de esas ca te go rías son pro pias de la Bi blio te co lo gía, otras son co munes a la Bibliotecología y a diferentes disciplinas relacionadas con ellas. En tre esas ca te go rías se en cuen tran, en sín te sis: actividad bibliotecaria, como categoría fundamental de la Bibliotecología; bibliotecario,fon dobibliotecario,préstamos, bi blio te cas, al can ce so cial de las bi blio te cas, como categorías principales propias también de la Bibliotecología; comu ni ca ción, li bro, lec tu ra, lec tor, demanda de los lec tores, orientación de la lectura, como categorías principales comunes a la bibliotecología y a otras disciplinas.

La estructura de la Bibliotecología socialista contemporánea está integrada por cinco disciplinas básicas: Bibliotecología ge ne ral, For ma ción de fon dos, Sis te ma de ca tálo gos, Traba jo con los lec to res y Org ni za ción de biblio te cas. ${ }^{8}$ La de fini ción del con te ni do de cada una de esas dis ci pli nas, sal vo la correspondiente a Sistemas de catálogos, ha sido estudiada en el plano nacional con el fin de conocer el alcance de cada una de ellas en su es ta do ac tual y de iden ti fi car, en al gu na me- di da, las pu bli ca cio nes que son más im por tan tes para ellas por suproductividad. ${ }^{9}$ Esos es tu dios han te ni do como base las definiciones ofrecidas por O.S. Chu ba rian, el análi sis de con tenido del Library and Information Science Abstracts ${ }^{10}$ y los propios resultados de las investigaciones realizadas por las bibliotecas públicas del país." Las precisiones alcanzadas has ta el mo men to, y que sir ven de base tam bién para el aná lisis que aho ra se pre sen ta, apa re cen re co gi das en for ma de epígrafes en el anexo 1 de este trabajo.

\section{EL SIS TE MA DE IN VES TI GA CIO NES DE LAS B I B LIO- TECAS PUBLICAS CUBANAS: SUS RESULTADOS}

Las in vestiga ciones de las bibliote cas pú blicas cu banas, en su estado actual, se agrupan en 6 líneas fundamentales:

- Evaluación del fondo bibliotecario y de la demanda no satisfecha.

— Dinámica de la lectura en las bibliotecas.

- Ti po lo gía y perfi les de la de man da de los lec to res de las bibliotecas.

- Métodos de trabajo con los lectores en las bibliotecas

- Componentes y factores económicos del trabajo de las bibliotecas

- Incidencia de la capacitación del bibliotecario en las funciones de las bibliotecas.

- Servicios de información para la cultura y las artes.

Durante el quinquenio 1981- 85 se eje cu taron, ade más, como tareas de un tema de investigación, estudios sobre los procesos de: selección, adquisición y descarte; conservación del patrimoniobibliográfico; au to matización deprocesos bibliotecarios; aplicación experimentaldelaclasificación biblioteco-bibliográfica de la URSS (CBB-URSS) en las bibliotecas públicas cubanas. ${ }^{12}$ Se efectuaron, asimismo, otras tareas de investigación relacionadas con el origen y evolución de las bibliotecas del país. Actualmente se realizan dos trabajos de as piran tu ra en el mar co de es tas in ves ti ga ciones: uno so bre la introducción en Cuba de la CBB-URSS, otro sobre modelación ma te má ti ca apli ca da a la ges tión del sis te ma na cio nal de bibliotecas públicas.

Los resultados alcanzados hasta el presente en las líneas, temas y tareas de investigación ejecutados, aparecen descritos bre ve men te en el ane xo 1 de este trabajo, agru pa dos se gún los contenidos definidos para cada una de las disciplinas que integran la estructura de la Bibliotecología.

8 Cfr.: Chubarian, O.S. Bibliotecología general. Op. cit. en Bibliografía p. 18-19.

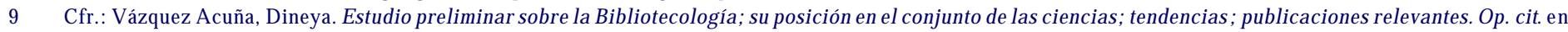
Bibliografía

10 Cfr. Library Association. Library Info rmation Science Abstracts. Op. cit. en Bibliografía

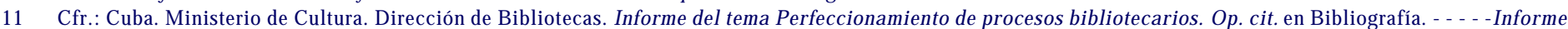

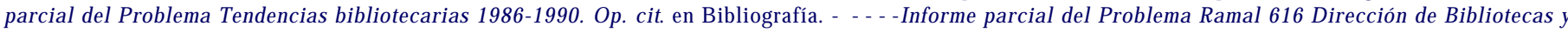
orientación de la lectura. Op. cit. en Bibliografía 
La re la ción de esos re sul ta dos con las ca te goías prin ci pa les de la Bibliotecología, identificadas en el epígrafe anterior, se comportan de la forma siguiente:

Figura2.1 Resultados relacionadosconcategorías propias y comunes

$\mathrm{a}=42 \%$ comunes

$\mathrm{b}=58 \%$ propias

El ma yor peso de los re sultados obtenidos se agrupa alrededorde las categorías propias de la Bibliotecología y, entre éstas, alrededor de las categorías de fondo bibliotecario y bi blioteca.

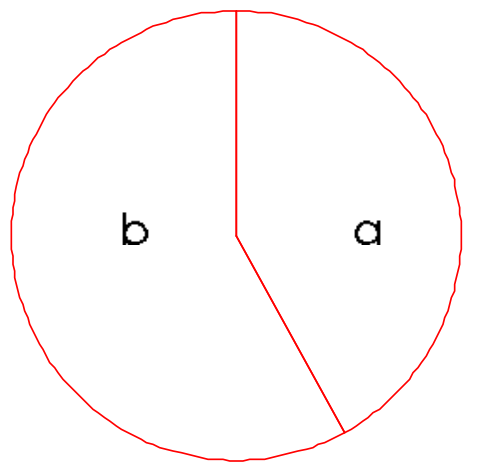

Figura 2.2 Resultados relacionados con categorías propias

\section{$\mathrm{a}=4 \%$ alcance \\ $\mathrm{b}=13 \%$ préstamos \\ $\mathrm{c}=17 \%$ bibliotecario \\ $\mathrm{d}=29 \%$ biblioteca \\ $\mathrm{e}=37 \%$ fondo biblio- tecario}

Las ca te go rías propias con que menos se relacionan los resultados alcanzados son, en orden decreciente: bibliotecario, préstamos y alcance social de las bibliotecas.

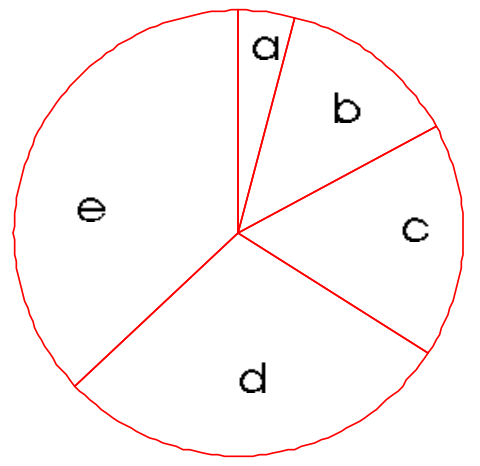

Figura 2.3 Resultados relacionados con categorías com u nes

$\begin{array}{ll}\mathrm{a}=3 \% & \text { comunicación } \\ \mathrm{b}=3 \% & \text { libro } \\ \mathrm{c}=9 \% & \text { lectura } \\ \mathrm{d}=18 \% & \begin{array}{l}\text { demanda de } \\ \text { los lectores } \\ \text { orientación de }\end{array} \\ \mathrm{e}=22 \% & \begin{array}{l}\text { la lectura } \\ \text { lectores }\end{array}\end{array}$

En las ca te go rías co mu nes a la Bibliotecología y a otras disciplinas, los resultados se agrupan mayoritaria-

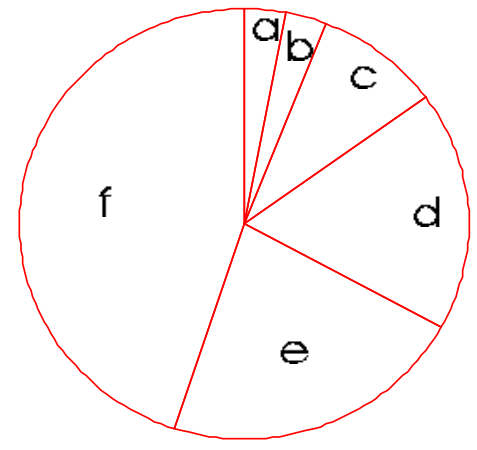
mente alrededor de las correspondientes a: lectores, orientación de la lectura y deman da de los lec to res. Son po cos los que se re la cio nan con las categorías de lectura, libro y comunicación (Ver anexo 2).
Figura 2.4 Resultados relacionados con las disciplinas de la Bibliotecología.

$\begin{array}{ll}a=3 \% & \begin{array}{l}\text { Sistema de catá- } \\ \text { logos }\end{array} \\ \mathrm{b}=20 \% & \begin{array}{l}\text { Trabajo con los } \\ \text { lectores }\end{array} \\ \mathrm{c}=20 \% & \begin{array}{l}\text { Formación de } \\ \text { fondos } \\ \text { Bibliotecología } \\ \text { general }\end{array} \\ \mathrm{d}=28 \% 29 \% & \begin{array}{l}\text { Organización de } \\ \text { bibliotecas }\end{array}\end{array}$

Comparados con los conte-

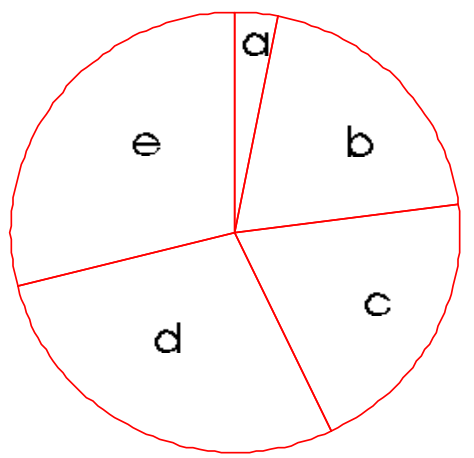
nidos de las disciplinasque integran la estructura de la Bibliotecología Socialista, la mayor can ti dad de re sul ta dos se re la cio nan, por or den, con las de Organización debibliotecas, Bibliotecologíageneral, Forma ción de fon dos y Tra ba jo con los lec to res. Sólo son re lativamente pobres los que se relacionan con la disciplina correspondiente a Sistema de catálogos (Ver anexo 3 ).

Figura 2.5 Grado de cubrimiento del contenido de las disciplinas en su conjunto

$$
\begin{array}{ll}
\mathrm{a}=29 \% & \text { No cubiertos } \\
\mathrm{b}=29 \% & \begin{array}{l}
\text { Cubiertos en } \\
\text { menor grado }
\end{array} \\
\mathrm{c}=42 \% & \begin{array}{l}
\text { Cubiertos en } \\
\text { mayor grado }
\end{array}
\end{array}
$$

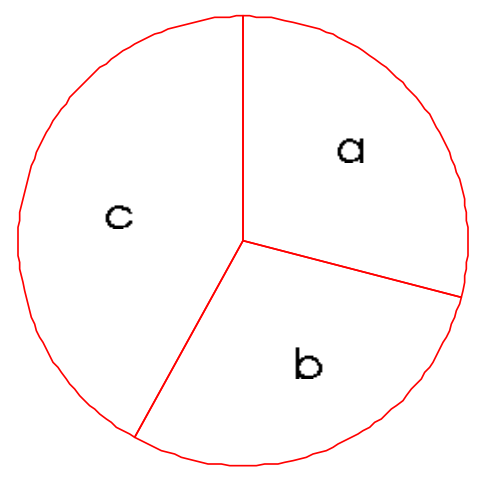

Erado decubrimien tode para esas disciplinas, en el marco de las investigaciones que se analizan, es bajo por lo ge ne ral. Un 58\% de los epí grafes que de fi nen esos con te ni dos no tienen asociados resultados, o estos son pobres desde el punto de vista cuantitativo y cualitativo (Ver anexo 4).

Las dis ci pli nas que pre sen tan me jor si tua ción son las co rrespondientes a Bibliotecologíageneral,Formación defondos y Trabajo con los lectores. Las de peor situación son Sistemas de ca tálogos y Orga ni za ción de bi bliotecas (Ver ane xo 4). 
Figura 2.6 Grado de cubrimiento del contenido de Bibliotecología general

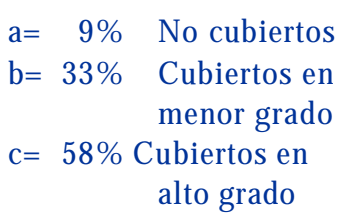
menor grado

$\mathrm{c}=58 \%$ Cubiertos en alto grado

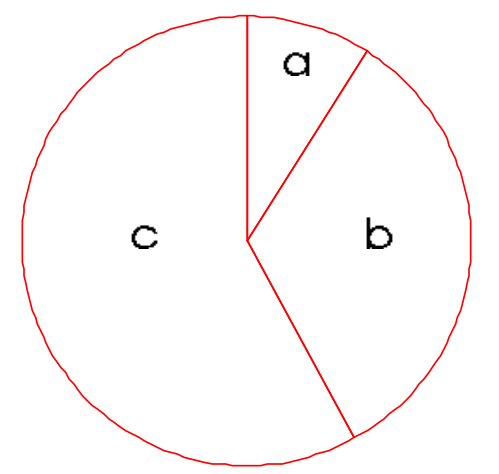

Fi gu ra 2.7 Gradodecu brimien todel con teni dode For mación de fondos

$$
\begin{array}{ll}
a=32 \% & \text { No cubiertos } \\
b=15 \% & \begin{array}{l}
\text { Cubiertos en } \\
\text { menor grado }
\end{array} \\
c=53 \% & \begin{array}{l}
\text { Cubiertos en } \\
\text { alto grado }
\end{array}
\end{array}
$$

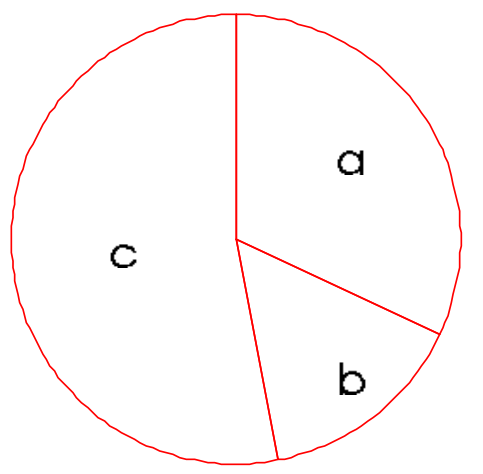

Figura2.8 Gradodecubrimien todelcontenidodeSistema de catálogos

$$
\begin{array}{ll}
\mathrm{a}=50 \% & \text { No cubiertos } \\
\mathrm{b}=25 \% & \begin{array}{l}
\text { Cubiertos en } \\
\text { menor grado }
\end{array} \\
\mathrm{c}=25 \% & \begin{array}{l}
\text { Cubiertos en } \\
\text { mayor grado }
\end{array}
\end{array}
$$

Figura 2.9 Grado de cubrimien todel con te ni do de Traba jo con los lectores

$$
\begin{array}{ll}
a=47 \% & \text { No cubiertos } \\
b=6 \% & \begin{array}{l}
\text { cubiertos en } \\
\text { menor grado }
\end{array} \\
c=47 \% & \begin{array}{l}
\text { Cubiertos en } \\
\text { mayor grado }
\end{array}
\end{array}
$$

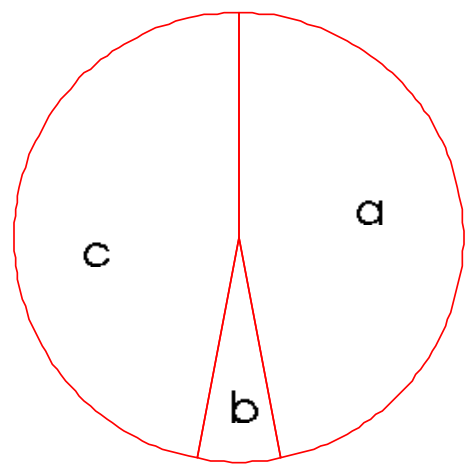

Figura 2.10 Grado de cubrimiento del contenido de Organización de bibliotecas

$$
\begin{array}{ll}
\mathrm{a}=23 \% & \text { No cubiertos } \\
\mathrm{b}=59 \% & \begin{array}{l}
\text { Cubiertos en } \\
\text { menor grado }
\end{array} \\
\mathrm{c}=18 \% & \begin{array}{l}
\text { Cubiertos en } \\
\text { mayor grado }
\end{array}
\end{array}
$$

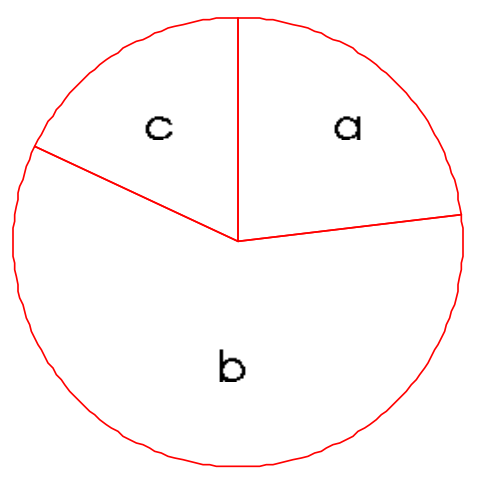

Debe tenerse en cuenta, no obstante, que las investigaciones en cur so de ben al can zar en el pre sen te quin que nio, se gún los objetivos programados, entre otros, resultados que corresponden a la esfera de la Organización de bibliotecas, por lo que la si tua ción des crita an te rior men te varia ráa cor to plazo.

El ane xo 5 de este tra ba jo pre sen ta, en for ma de ta bla, los conte ni dos de cada dis ci pli na en los que no se han ob te ni do re sultados o los que están pobremente representados por éstos.

Las cau sas que in ci den ma yor men te en la si tua ción an tes descri ta y los con te ni dos afec ta dos por ellas pue den agru par se en la forma siguiente:

1. El programa de investigaciones que ahora se analiza corresponde sólo a las bibliotecas públicas, por lo que escapan al re fle jo de la si tua ción real de cada dis ci pli na en el país, los resultados que se obtienen en las investigaciones realizadas por otros tipos de biblio te cas y los que pu die ran ob te nerse de un programaúniconacionaldeinves tigacionesbibliotecológi cas. En tre los con te ni dos que se ven afec ta dos por es tas causas se encuentran: 
- Tipología de las bibliotecas; bibliotecas para distintos tipos de lec to res; ins ti tu ciones para la for ma ción de biblio tecarios. (Bibliotecología General)

- Distribución de fondos según tipos de bibliotecas. (Formación de fondos)

- Servi cios a lec to res de dis tin tos ti pos de bi blio te cas. (Trabajo con los lectores)

- Estructuras de los distintos tipos de bibliotecas; edificios de bibliotecas; calificación del personal; remuneración. (Organización de bibliotecas)

En las investigaciones realizadas por la Universidad de La Ha ba na y por la Es cue la Na cio nal de Téc ni cos de Biblio te cas del Ministerio de Cultura se han alcanzado diversos resultados referidos a lacalifica ción del biblio te cario. La Di rec ción de Bibliotecas ha participado activamente en las comisiones de especialistas de esas investigaciones.

2. La je cu ción de in ves ti ga ciones aplica das rela ciona das con labase téc ni co ma terial de la ac ti vi dadbibliotecariare quieren de re cur sos que no se en cuen tran ge ne ra li za dos en el sis te ma. Estasituación afec ta elde sarrolloul terior de es tu dios sobre:

- Conservación del patrimonio bibliográfico. (Formación de fondos)

- Servicios de reproducción de documentos. (Trabajo con los lectores)

- Técnica y tecnología de bibliotecas (incluida la automatización de procesos bibliotecarios). (Organización de bibliotecas)

3. Determinados te mas de in ves ti gación re quie ren la in te gración de diversas direc ciones es pecializa das del Mi nis te rio de Cul tu ra y de otros or ga nis mos es ta ta les, lo que no se ha lo grado ple na men te. En tre los con te ni dos afec ta dos por esta cau sa se encuentran:

- El siste madeabas tecimien to a las bibliotecas; dis tribución de fon dos se gún ti pos de bibliotecas. (Formación de fondos)

- Servi cios a lec to res en dis tin tos ti pos de bi blio te cas. (Trabajo con los lectores)

- La nor ma ción, nor ma li za ción y le gis la ción de la ac ti vi dad bibliotecaria. (Organización de bibliotecas)

Con res pec to a este úl ti mo epí gra fe es ne ce sa rio acla rar que el programa de normalización de la actividad en el país, que se hadesarrollado vertiginosamente en el último decenio, y que se apoya en investigaciones propias del proceso de elaboración de nor mas, no apa re ce re fle ja do, por lo ge ne ral en el plan temático de investigaciones.

4. Las investigaciones de las bi blio tecas públicascubanases- tán orientadas principalmente hacia los contenidos específicos de la Bibliotecología, como disciplina relativamente independiente de las ciencias sociales, y no incluyen con la amplitud requerida los que se insertan en los puntos de contacto con otras ciencias, especialmente con aquellas que le son contiguas. Se afectan así contenidos tales como:

- Relaciones de la Bibliotecología con otras disciplinas. (Bibliotecología general y todas las disciplinas relacionadas con la Bibliotecología, mencionadas a través de este trabajo)

- Pa pel so cial de las bi blio te cas comoins ti tu cio nes ideo ló gicas e informativas. (Bibliotecología general,Informática, Sociología)

- Ti pología de los do cumen tos. (Formación de fondos, Bibliología, Bibliografología, Informática)

- Todos los contenidos de la disciplina Sistema de catálogos (Bibliografología, Informática)

- Tipos y hábitos de lectura. (Trabajo con los lectores, Pedagogía, Sociología, Psicología, Bibliología, Bibliografología e Informática)

- Información biblioteco-bibliográfica. (Trabajos con los lectores y trabajos de referencia, Bibliografología, Informática)

— Los te mas de téc ni cas y tec no lo gía bi blio te caria. (Organiza ción de biblio tecas, disciplinastec nológicas)Limitadas también por condiciones materiales, como fue señalado anteriormente.

Debe aclararse que el programa actual de investigaciones de las bi blio te cas pú bli cas in clu ye ya es tu dios que se in ser tan en el pun to de con tac to de la Bi blio te co lo gía, la In for má ti ca y al gunas disciplinas tecnológicas, a través del tema "servicios de in for ma ción para la cul tu ra y las ar tes", cu yos pri me ros resultados deben obtenerse a fines del presente quinquenio.

5. No han sido in clui dos en los pla nes de in ves ti ga ción, con la amplitud suficiente, estudios sobre:

- El can je, los do na ti vos, la or ga ni za ción y el con trol del fondobibliotecarioy su procesamien tofísico.(For ma ción de fondos)

- Préstamos interbibliotecarios y en extensión; orientación so bre el uso de las bi blio te cas. ( Traba jos con los lec to res)

No obstan te, en fe cha re cien te, Cuba ha sido de sig na da como coejecutora de una investigación de países socialistas sobre las relaciones entre el préstamo interbibliotecario y el canje internacional, lo que contribuirá a enriquecer los resultados obenidos en estos epígrafes, en un futuro cercano.

- Al can ce de las bi blio te cas. (Organizacióndebibliotecas, Bibliotecología general) 
6. Se encuentran en curso investigaciones cuyos resultados son aún li mi ta dos, pero que al can za rán ma yor ri que za a fi nes del quinquenio 1986-1990. Estas investigaciones se encuentran relacionadas con los contenidos de: Planificación, organización, control y ejecución práctica de las funciones de las bibliotecas y sus costos. (Organización de bibliotecas)

Los resultados obtenidos se relacionan en ocasiones con los con te ni dos de más de una de las dis ci pli nas de la Bi blio te co logía.En trees tos re sul ta dos son mayoritarios aquellos que tienen como una de las dis ci pli nas co mu nes a la de no mi na da Organiza ción debiblio te cas. Se pone de ma ni fies to así que el pro grama de investigaciones satisface el objetivo central para el que fue con ce bi do, esto es, el perfec cio na mien to de la ac ti vi dad de las bibliote cas públicas, pues to que los re sul ta dos que permiten la consecución de ese obje ti vo se en marcan, o se re la cio nan de una forma u otra con el contenido de dicha disciplina.

En tre los re sul ta dos que son co mu nes a la Bibliotecologíageneraly a las de más dis ci pli nas que in te gran la es truc tu ra de la Bibliotecología, se encuentran básicamente los que corresponden a principios y méto dos dein vestiga ción bibliote cológica. Esto constituye una expresión del sustento teórico bibliotecológico en que se basan las investigaciones aplicadas en los estudios de fondos, del trabajo con los lectores y de la organización de las bibliotecas.
El ane xo 6 mues tra un cua dro es ta dís ti co que re su me el compor ta mien to de los re sul ta dos de uti li dad co mún a va rias disciplinas de la Bibliotecología.

Por último, se presentan en forma de dia gra ma los ne xos sisté mi cos que sees tablecen en tre los resulta dos fun da mentales de las líneas de investigación de las bibliotecas públicas del país, así como la forma en que esos resultados se relacionan con la actividad prác tica de esas ins ti tu ciones (cfr. dia grama, figura 11).

La eje cu ción de las ac ti vi da des prác ti cas de ri va das de los resultados de las investigaciones se orientan en función de los lineamientostrazados por el Partido y el Es ta do para el de sarrollo so cioe co nó mi co, de for ma tal que se co rres pon dan con ellos. Esta orientación cons ti tu ye el me dio de lo grar el má ximo ri gor cien tífi co de su apli ca ción, en tan to esos li nea mientos se co rres pon den con el curso ob je ti vo del de sa rrollo so cial guiado conscientemente.

Figura 2.11 Nexos entre los resultados fundamentales de las líneas de investigación y forma en que se relacionan con la actividad práctica de las bibliotecas.

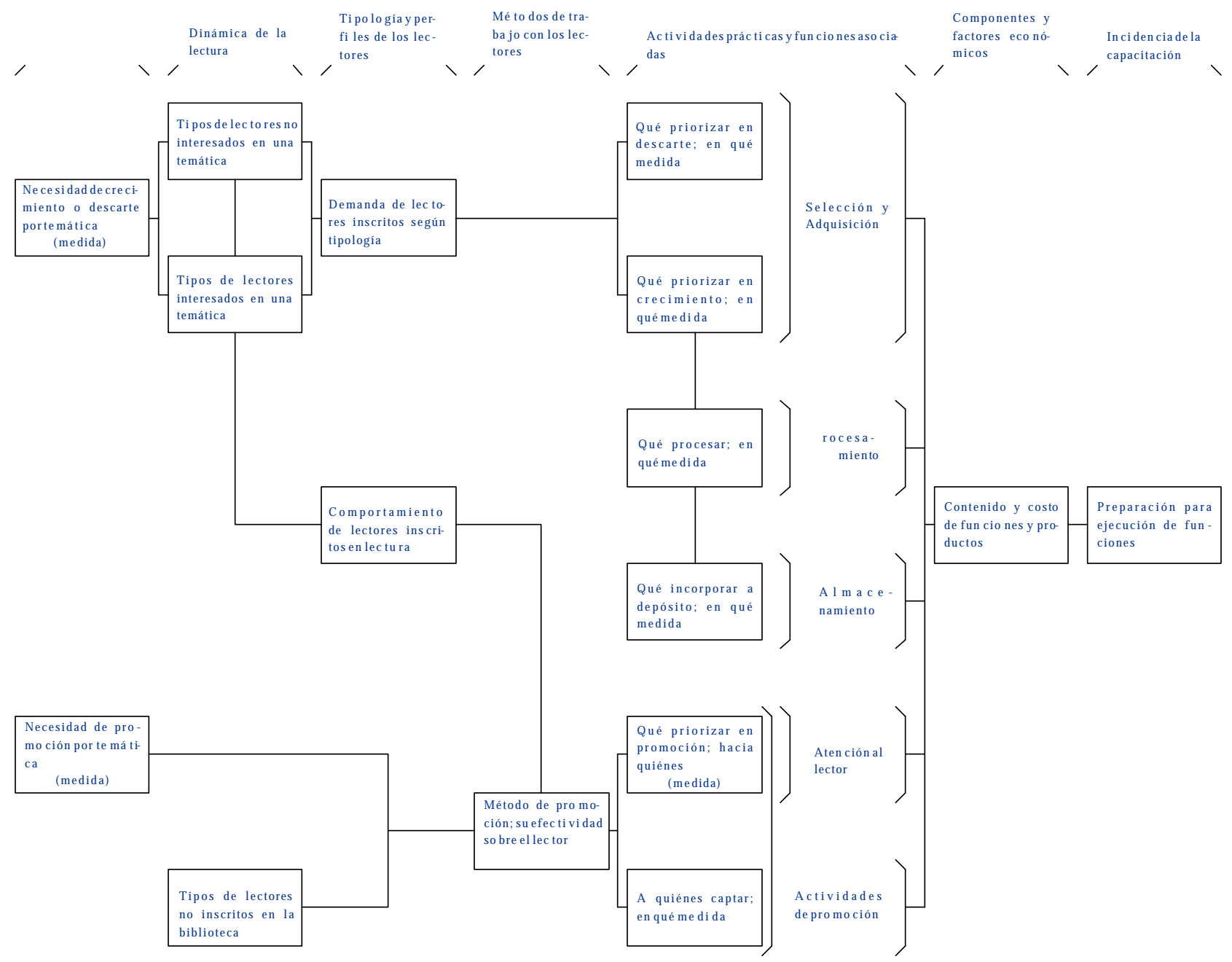


LA ORGANIZACION DEL TRABAJO CIENTIFICO EN EL SISTEMA DE BIBLIOTECAS PUBLICAS

El trabajocien tífico de las biblio te cas pú blicas cu ba nas se organiza en forma de problemas, temas y tareas, como quedó expuesto en el epígrafe anterior. Se encuentra dirigido de la forma que muestra el diagrama siguiente:

Figura3.1 Di rec ción de las in ves ti ga ciones en el sis te ma de bibliotecas públicas.

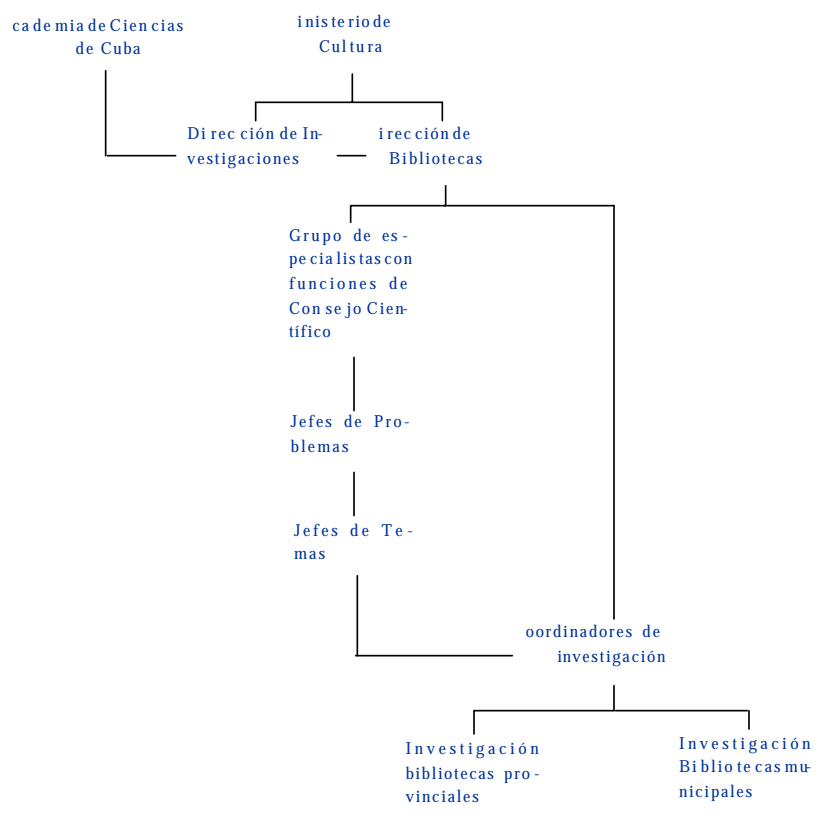

El tra ba jo se ex tien de a tra vés de to das las pro vin cias, aun que al gu nas de ellas al can zan más de sa rro llo que otras. Ese de sarrollo de si gual se ma ni fies ta, en tre otros fac to res, en las po sibilidades que ofrecen los colectivos provinciales para la selección de cuadros encargados de coordinar y dirigir in ves tigacio nes, y en el gra do de par tici pa ción de las biblio tecas provinciales y municipales en estas tareas.

Actualmente secuentacon coordinadores de in vestigaciones bibliotecológicas, con cierto grado de experiencia, en nueve de las cator ce pro vin cias; cua tro pro vin cias cuen tan con co ordi na do res que re cién ini cian sus fun cio nes y una ca re ce de coor di na dor, al igual que el mu ni ci pio es pe cial de Isla de la Juventud. Hasta el momento se han designado como jefes de temas de investigación a bibliotecarios de cinco provincias.

El cuadro que se ofrece a continuación muestra el grado de participación de lasbibliotecas provinciales y municipalesen el pro gra ma de in ves ti ga ción que se vie ne de sa rro llan do des de 1981. Nótese el bajo nivel de participación de lasbibliotecas municipales en ese programa.
Tabla. Par ti ci pa ción de las bi blio te cas, se gún su tipo, en el programa de investigaciones. ${ }^{13}$

\begin{tabular}{||l|c|c|c|c||}
\hline \hline Tema o tarea & \multicolumn{2}{|c|}{$\begin{array}{c}1981-1985 \\
\text { Bibliotecas }\end{array}$} & \multicolumn{2}{c|}{$\begin{array}{c}1986-1987 \\
\text { Bibliotecas }\end{array}$} \\
\hline & $\begin{array}{c}\text { Provin- } \\
\text { ciales }\end{array}$ & $\begin{array}{c}\text { Munici- } \\
\text { pales }\end{array}$ & $\begin{array}{c}\text { Provin- } \\
\text { ciales }\end{array}$ & $\begin{array}{c}\text { Munici } \\
\text { pales }\end{array}$ \\
\hline Evaluación de fondos & $62 \%$ & $3 \%$ & $38 \%$ & $9 \%$ \\
\hline Evaluación de la desiderata & $38 \%$ & $1 \%$ & $62 \%$ & $7 \%$ \\
\hline Dinámica de la lectura & $46 \%$ & $3 \%$ & $62 \%$ & $3 \%$ \\
\hline $\begin{array}{l}\text { Tipología de lectores y perfiles } \\
\text { de la demanda }\end{array}$ & $38 \%$ & $3 \%$ & $31 \%$ & $5 \%$ \\
\hline Trabajos con los lectores & & & $46 \%$ & $14 \%$ \\
\hline $\begin{array}{l}\text { Componentes del sistema de di- } \\
\text { rección* }\end{array}$ & & & $8 \%$ & $2 \%$ \\
\hline Factores económicos* & & & $31 \%$ & $7 \%$ \\
\hline Incidencia de la capacitación & $62 \%$ & & $54 \%$ & \\
\hline \hline
\end{tabular}

* investigaciones ini cia das en el quin que nio 1986-1990

* estudiosrealizados por las bibliotecas provinciales, que incluyen la situación de los municipios

Los resultados de estas investigaciones se presentan y discuten en eventos científicosnacionales de bibliotecas públicas, que se celebran dos veces por quinquenio y están precedidos de jornadas provinciales. Se participa, asimismo, en eventos convocados por otras instituciones y organizaciones.

En el programa de investigaciones que ahora se analiza han ju ga do un pa pel im por tan te los tra ba jos de gra do de alum nos de laEs cue la Na cio nal de Téc ni cos de Bi blio te cas del Mi nis terio de Cultura, y los trabajos de diploma de alumnos del Depto. de Información Científico Técnica y Bibliotecología de la Universidad de La Habana. Esos estudianteshantenido a su cargo tareas que contribuyeron a la solución de diversos problemas que no hubiese sido posible abordar con la fuerza de trabajo de las biblio te cas pú blicas. El per so nal del sis te ma que eje cu tael plan de in ves tigaciones com par te esta ta reacon otras, propias de la actividad diaria de las bibliotecas.

Varios informes de investigación, o versiones de ellos, han sido publicados en revistas nacionales y extranjeras de la especialidad.

Un factor importante que ha incidido en el desarrollo de las in ves ti ga ciones de las bi blio te cas públi cas cu ba nas ha sidola incorporación del Ministerio de Cultura al trabajo conjunto que rea li zan los paí ses so cia lis tas en la es fe ra de esas ins ti tur ciones. Tal incorporación se produjo a fines del quinquenio 1976- 1980 y su incidencia en las investigaciones nacionales será objeto, próximamente, de un estudio como el que ahora se presenta. 


\section{CONCLUSIONES Y RECOMENDACIONES}

Algunas líneas de investigación propias del contenido de las dis ci pli nas que in te gran la Bi blio te co lo gía sólo po drán abordarse en la medida en que se desarrolle la base técnico material de las bibliotecas.

El análisis de las investigaciones de las bibliotecas públicas cubanas por sí sólo no permite obtener un cuadro completo del desarrollo de las investigaciones bibliotecológicas del país, pues to que es ca pan a él los tra ba jos rea li za dos por otros sistemas bibliotecarios. Este ais la mien to pue de con du cir a la duplicación de esfuerzos o a la omisión de algunas líneas de in ves ti ga ción pro pias de las dis tin tas dis ci pli nas que in te gran la es truc tu ra de la Bi blio te co lo gía. Se hace ne ce sa rio con formar un plan integral de colaboración y análisis de resultados de estas investigaciones, al que pueden contribuir la Academia de Ciencias, como rector metodológico de las investigaciones del país, y la Asociación Cubana de Bibliotecarios, a tra vés de su sec ción de Teoría e In ves ti ga ciones Biblio te co lógicas.

Las investigaciones de las bibliotecas públicas cubanas se hancen trado principal men te en los con te ni dos es pecífi cos de la Biblio te co lo gía. Para su de sa rro lloul te rior se re quie re de la creación de equipos y programas multidisciplinarios con el fin de diseñar y ejecutar problemas de investigación correspon dien tes a los pun tos de con tac to en tre la Biblio te co lo gíay otras dis ciplinas, muy es pecial men te en tre la Biblio te cología y la Biblio gra fo lo gía, dada la in ter de pen den cia que se pro duce en la práctica entre la actividad bibliotecariay la actividad bibliográfica. Esto contribuirá a alcanzar mayores precisiones en los con teni dos de la dis ciplinade nomina da Sis te ma de Catálogos y a obtener resultados sobre los contenidos de información biblioteco-bibliográfica y trabajo de referencia, correspondientes a la disciplina de Trabajo con los lectores. Ese en fo que per mi ti rá, ade más, abor dar es tu dios so bre el abastecimientoa las bibliotecas, la normación, la normalización y la legislación de la actividad bibliotecaria, queestudia la disciplina Organización de bibliotecas.

Los programas multidisciplinarios también permitirán ampliar los estudios sobre el alcance social de las bibliotecas, con el fin de de fi nir el pa pel que jue gan en el con tex to na cional comoins ti tu cionesideo ló gi case informativas, ru brosque aún no han sido abor da dos a ple ni tud, y que se co rres pon den con los contenidos de las disciplinas Organización de bi bliotecas y Bibliotecología general.

Por otra par te, se hace evi den te que en tan to el pro ce so de nor- ma li za ción cuen ta en tre sus ba ses con los re sul ta dos de las investigaciones científicas, los planes de esa actividad deben ser precedidos por el plan de investigaciones correspondientes.

Con la concepción, la organización y los recursos actuales es posible orien tar el pro gra ma de in ves ti ga cio nes de las bi bliotecas públicas hacia la obtención de nuevos resultados relacionadosconepígrafes pobrementere presentadoscorrespondientes a Formación de fondos, Trabajo con los lectores y Organización de bibliotecas.

Los resultados alcanzados hasta el momento en la organización del tra ba jo de in ves ti ga ción de las bi blio te cas pú bli cas a tra vés del país mues tran la ne ce si dad de in cre men tar el nú mero y la calificación de cuadros capaces de coordinar y dirigir ta reas de in ves ti ga ción, y de in cor porar al tra bajo cien tífico a todas las bibliotecasmunicipales en el plazo más bre ve posible.

Esto último permitirá que dichas instituciones se beneficien plenamente con los resultados que se obtienen mediante la aplicación de los métodos de investigación diseñados, puesto que no puede perderse de vista que cada una de ellas presenta particularidades propias, cuyo reflejo objetivo sólo puede ser logrado en su entorno específico, con relativa independencia delasten dencias que pre valen cen ani vel del sis te ma nacio nal.

Puede con cluirse, asi mis mo, que, in de pen dientemen te de las limitaciones y recomendaciones apuntadas en los párrafos an teriores, el programade in vestigaciones analiza do se hadesarrollado con la orientación prevista, en tanto ha permitido obtenerresultados relacionados directamente con el objetivo cen tral del pro gra ma, esto es, el per fec cio na mien to de la ac tivi dad de las bi blio te cas pú bli cas. En esa orien ta ción ha ju ga do un papel principal la cohesión sistémica que existe entre los resultados de cada tema o tarea de investigación y entre ellos y la actividad práctica de las bibliotecas.

Los fundamentos teóricos y metodológicos adoptados, sujetos tam bién a de sa rro llo, han mos tra do su uti li dad para la concepción sistémica del programa de investigaciones y para su evaluación, como se pone de manifiesto en este trabajo. No obstante, es necesario dedicar más esfuerzos a la investigación teórica de la Bibliotecología en el plano nacional, sin abandonar las investigacionesaplicadas. Ese trabajo no es tará exen to de di fi cul ta des da das las dis tin tas po si cio nes y contra dic ciones que exis ten para en focar el con te ni do, pa pely lugar de esta dis ci pli na en el con jun to de las cien cias y al pro pio ritmo al que estas se desarrollan en nuestros días. 


\section{BIBLIOGRAFIA}

Par ti do Co mu nis ta de Cuba, Con gre so, 20., 1980. - Re soluciones aprobadasporelIICongreso del Partido Comunis ta de Cuba/Par ti do Co mu nis ta de Cuba. - La Ha ba na: Edi to ra Política, 1981. - p.

Academia de Cien cias de Cuba. Ins ti tu to de Do cu menta ción e In for ma ción Científica y Técnica. — Diccionariodetérminos de Informática; español, ruso, inglés. — La Ha ba na: Ins ti tu to de Documentación e Información Científica y Técnica, 1977. — 2t.

Bol'schchaya sovetskaya ehntsiklopediya. - 3 iz. - Moskva: Sovetskaya ehntsiklopediya, 1973. - $26 \mathrm{t}$.

Cuba. Minis terio de Cul tura. Direc ción de Bibliotecas. - Informe deltema Perfeccionamientode procesos bibliotecarios / Dirección de Bibliotecas. — [1985] — 250h.

Mecanografiado.

- - - -Informe parcial del problemaTendencias bibliotecarias 1986-90 / Di rec ción de Biblio tecas. - [1987] - 45h.

Mecanografiado.

- - - Informe parcial del proble ma ramal616Dirección de bibliotecas yorien tación de la lectura. - [1987] - $57 \mathrm{~h}$.

Mecanografiado.

Chu barian, O.S. - Bibliotecologíageneral/O.S. Chu ba rian; [trad. An to nio Tris tá Pérez]. — La Habana: Editorial Científico Técnica, [1981]. — 367 p.

EncuentroCientífico Bibliotecológico, 2o., La Habana, 1981.—Resúmenes. — La Ha ba na: Dirección de Bibliotecas del Ministerio de Cultura, 1981. - 65p.

EncuentroCientífico Bibliotecológico, 3o., La Haba na, 1983. - Resúmenes. — La Ha ba na: Dirección de Bibliotecas del Ministerio de Cultura, 1983. - 117 p.

EncuentroCientífico Bibliotecológico, 4o., La Habana, 1985. - Resúmenes. — La Ha ba na: Dirección de Bibliotecas del Ministerio de Cultura, 1985. - 73 p.

EncuentroCientífico Bibliotecológico, 5o., La Habana, 1987. - Resúmenes. — La Ha ba na: Dirección de Bibliotecas del Ministerio de Cultura, 1987. — 70 p.

Library Association. Library and Information Science Abstracts / Library Association. - London: University Press, 1985. - 12v.

Shamurin, E.I. "Slo var' Kni go vedcheskikh ter mi nov." En:Ba renhaum, I.E. i T.E. Davydo va. Istoriya Knigi. — Moskva: Kniga, 1971. — 240 p.

Sokolov, A.V. "Sistema de ciencias comunicativo-informativas." Actualidades de Información Científica y Técnica. — La Habana : xxvii, 3(128): 3-15, junio 1986.

Vázquez Acu ña, Di ne ya. Estudiopre liminar sobre la Bibliote cología; supo siciónenel conjunto de las ciencias; publicaciones relevantes: Trabajo de Diploma / Dineya Vázquez Acuña, 1987. - $72 \mathrm{~h}$.

Mecanografiado. 


\section{ANEXO I}

Disciplinas que integran las estructura de la Bibliotecología socialista contemporánea:

sus contenidos y resultados obtenidos en cada uno de ellos

por las investigaciones de las bibliotecas públicas cubanas

\begin{tabular}{|c|c|c|c|c|}
\hline CONTENIDO & $\begin{array}{l}\text { GRA- } \\
\mathrm{DO}^{*} \\
\end{array}$ & $\begin{array}{l}\text { DESCRIPCION DE } \\
\text { RESULTADOS } \\
\end{array}$ & $\begin{array}{c}\text { TRABAJO DE } \\
\text { INVESTIGACION }\end{array}$ & $\begin{array}{c}\text { TIPO DE } \\
\text { INVESTIGACION }\end{array}$ \\
\hline \multicolumn{5}{|c|}{ BIBLIOTECOLOGIA GENERAL } \\
\hline $\begin{array}{l}\text { Papel social de las bibliotecas } \\
\text { como instituciones ideológicas } \\
\text { einformación. }\end{array}$ & $\mathrm{m}$ & $\begin{array}{l}\text { Forma de comunicación social que organiza y } \\
\text { orientaelusodellibrocomopropiedad colectiva. }\end{array}$ & $\begin{array}{l}\text { Punto de partida para la con- } \\
\text { cepción de los trabajos de in- } \\
\text { vestigación. }\end{array}$ & \\
\hline Ti pología de las bi blio tecas. & $\mathrm{m}$ & $\begin{array}{l}\text { Identificacion de las bibliotecas existentes en } \\
\text { Cuba an tes del triun fo de la Re vo lu ción y su ti po- } \\
\text { lo gía. }\end{array}$ & $\begin{array}{l}\text { Origen y evolución de las bi- } \\
\text { bliotecas en Cuba. } \\
\text { Análi sis de ín dices de re vis tas } \\
\text { bibliotecológicas. }\end{array}$ & $\begin{array}{l}\text { Tema independiente } 1981 \text {. } \\
1985 . \\
\text { Trabajos de grado de la ENTB. }\end{array}$ \\
\hline $\begin{array}{l}\text { Bibliotecas para distintos tipos } \\
\text { de lectores. }\end{array}$ & $\mathrm{m}$ & $\begin{array}{l}\text { Identificaciónde bibliotecas para distintos tipos } \\
\text { de lectores existentes en Cuba antes del triunfo } \\
\text { de la Revolución. }\end{array}$ & $\begin{array}{l}\text { Origen y evolución de las bi- } \\
\text { bliotecas en Cuba. } \\
\text { Análisis de ín dices de re vis tas } \\
\text { bibliotecológicas. }\end{array}$ & $\begin{array}{l}\text { Temaindependiente 1981-85. } \\
\text { Trabajos de grado de la ENTB. }\end{array}$ \\
\hline \multirow[t]{2}{*}{$\begin{array}{l}\text { Tendencias de desarrollo de la } \\
\text { actividadbibliotecaria. }\end{array}$} & M & $\begin{array}{l}\text { Ten den cias en la com po si ción de loslectores ins- } \\
\text { cri tos en las bi blio te cas pú bli cas, en re la ción con } \\
\text { la com po si ción de la po bla ción, como ex pre sión } \\
\text { del al can ce de las bi blio te cas. }\end{array}$ & Dinámica de la lectura. & $\begin{array}{l}\text { Ta rea del tema de PPS 1981- } 85 . \\
\text { Tema de PP 1986- } 90 .\end{array}$ \\
\hline & & $\begin{array}{l}\text { Ten den cias en el uso de losfondosbibliotecarios } \\
\text { por parte de los bibliotecarios por parte de los } \\
\text { lectores inscritos en las bibliotecas públicas, a } \\
\text { partir del sis te ma de préstamos in ter nos y ex ter- } \\
\text { nos. }\end{array}$ & Evaluación de fondos. & Ibid. \\
\hline $\begin{array}{l}\text { Le yes que ri gen el de sa rro llo de } \\
\text { la actividadbibliotecaria. }\end{array}$ & M & $\begin{array}{l}\text { La ne ce sa ria de pen den cia de la actividadbiblio- } \\
\text { tecaria de las condiciones políticas, económicas } \\
\text { y culturales. El principio fundamental de la co- } \\
\text { rrespondenciaactiva entre fondo bibliotecario y } \\
\text { la demanda de los lectores. }\end{array}$ & $\begin{array}{l}\text { Pun tos de parti da para el análi- } \\
\text { sis e interpretación de la base } \\
\text { de da tos y las re lacionesiden ti- } \\
\text { ficadas en los trabajos de in- } \\
\text { vestigación. }\end{array}$ & \\
\hline \multirow[t]{6}{*}{$\begin{array}{l}\text { Investigaciones bibliotecológi- } \\
\text { cas: sus métodos. }\end{array}$} & M & $\begin{array}{l}\text { Mé to do para pon de rar la in ci den cia de la ca pa ci } \\
\text { ta ción y sus for mas en el de sa rro llo de las fun cio- } \\
\text { nes de las bibliotecas por par te de bibliotecarios } \\
\text { dediferentescalificaciones. Sistemaau to matiza- } \\
\text { do. }\end{array}$ & Incidencias de lacapacitación. & $\begin{array}{l}\text { Ta rea de tema PPS } 1981-85 . \\
\text { Tema de PP 1986- } 90 .\end{array}$ \\
\hline & & $\begin{array}{l}\text { Método para evaluar el fondo bibliotecario con } \\
\text { sumovimien to (préstamos) y la demandade los } \\
\text { lectores no satisfecha. Algoritmo para definir } \\
\text { prioridades en la adquisición, el descarte o la } \\
\text { orientacióndelalectura para ele varelvolumen } \\
\text { de los préstamos. Sistemaautomatizado. }\end{array}$ & Evaluación de fon dos. & Ibid. \\
\hline & & $\begin{array}{l}\text { Método para identificar componentes del fondo } \\
\text { bibliotecario que tienen préstamos significati- } \\
\text { vos. }\end{array}$ & & $\begin{array}{l}\text { Trabajo de Diploma de ICTB- } \\
\text { UH. }\end{array}$ \\
\hline & & $\begin{array}{l}\text { Mé to dos para eva luar la de man da de los lec to res } \\
\text { nosa tis fe cha. Sis te ma au to ma ti za do. }\end{array}$ & Evaluación de la desiderata. & $\begin{array}{l}\text { Ta rea de tema de PPS 1981- } 85 . \\
\text { Tema de PP 1986- } 90 . \\
\text { Trabajo de diplomaICTB-UH. }\end{array}$ \\
\hline & & $\begin{array}{l}\text { Método para el análisis de los factores físicos, } \\
\text { químicos y biológicos que afectan la conserva- } \\
\text { ción del fondobibliotecario. }\end{array}$ & $\begin{array}{l}\text { Conservación del patrimonio } \\
\text { bibliográfico. }\end{array}$ & Ta rea de tema de PPS 1981- 85 . \\
\hline & & $\begin{array}{l}\text { Mé to do para de fi nir la ti po lo gía y la de man da de } \\
\text { los lec tores. }\end{array}$ & $\begin{array}{l}\text { Categorías y perfiles de lecto- } \\
\text { res. }\end{array}$ & $\begin{array}{l}\text { Ta rea de tema de PPS } 1981-85 . \\
\text { Tema de PP 1986- } 90 .\end{array}$ \\
\hline
\end{tabular}

* $\mathrm{M}=$ mayor grado $\mathrm{m}=$ menor grado $\mathrm{O}=$ no cubrimiento 


\begin{tabular}{|c|c|c|c|c|}
\hline CONTENIDO & $\begin{array}{l}\text { GRA- } \\
\mathrm{DO}^{*}\end{array}$ & $\begin{array}{l}\text { DESCRIPCION DE } \\
\text { RESULTADOS } \\
\end{array}$ & $\begin{array}{c}\text { TRABAJO DE } \\
\text { INVESTIGACION }\end{array}$ & $\begin{array}{c}\text { TIPO DE } \\
\text { INVESTIGACION }\end{array}$ \\
\hline & & $\begin{array}{l}\text { Mé to do para de fi nir el gra do de efec ti vi dad de las } \\
\text { actividadesde orientación de la lecturaorganiza- } \\
\text { dos para distintos tipos de lectores. }\end{array}$ & $\begin{array}{l}\text { Mé to dos de tra ba jo con los lec- } \\
\text { tores. }\end{array}$ & Tema de PR 1986-90. \\
\hline & & $\begin{array}{l}\text { Método para definir y ponderar el contenido de } \\
\text { los com po nen tes del sis te ma de di rec ción de las } \\
\text { bibliotecas. }\end{array}$ & $\begin{array}{l}\text { Componentes del sistema de } \\
\text { dirección de las bibliotecas. }\end{array}$ & Ibid. \\
\hline & & $\begin{array}{l}\text { Sistema automatizado para el procesamiento de } \\
\text { los da tos uti li za dos en los es tu dios de lectores. }\end{array}$ & Dinámica de la lectura. & $\begin{array}{l}\text { Tarea de tema de PPS 1986-90. } \\
\text { Tema de PP 1986-90. } \\
\text { Trabajo de diplomaICTB-UH. }\end{array}$ \\
\hline & & Mé to dos para me dir elal cance de las bibliotecas. & $\begin{array}{l}\text { Modelación matemática apli- } \\
\text { ca da a la ges tión de las bi blio- } \\
\text { tecas públicas. }\end{array}$ & Trabajode aspirantura 1986-90. \\
\hline $\begin{array}{l}\text { Relacionesdela Bibliotecología } \\
\text { con otras cien cias. }\end{array}$ & $\mathrm{m}$ & $\begin{array}{l}\text { Relaciones de la Bibliotecología con la Biblio- } \\
\text { grafología, la Informática, la Bibliología, la Pe- } \\
\text { dagogía y la Matemática. }\end{array}$ & $\begin{array}{l}\text { Posición de la Bibliotecología } \\
\text { en el conjunto de las ciencias. } \\
\text { Modelación matemática apli- } \\
\text { ca da a la ges tión de las bi blio- } \\
\text { te cas públicas. }\end{array}$ & $\begin{array}{l}\text { Trabajo de Diploma de ICTB- } \\
\text { UH. }\end{array}$ \\
\hline \multirow[t]{3}{*}{ Bibliotecarios. } & M & $\begin{array}{l}\text { Ni veles de capacitación delbibliotecario para el } \\
\text { desarrollo de su trabajo, según funciones, según } \\
\text { categoría ocupacional y según tipos de bibliote- } \\
\text { cas. }\end{array}$ & In ciden cia de la ca pa ci ta ción. & $\begin{array}{l}\text { Ta rea de Tema de PPS 1981- } 85 . \\
\text { Tema de PP 1986-90. }\end{array}$ \\
\hline & & $\begin{array}{l}\text { Identificación de publicaciones seriadas extran- } \\
\text { jeras re le van tes parala Biblio te co lo gía en ge ne- } \\
\text { ral y para sus dis tin tas dis ci pli nas. }\end{array}$ & $\begin{array}{l}\text { Posición de la Bibliotecología } \\
\text { en el con jun to de las cien cias }\end{array}$ & $\begin{array}{l}\text { Trabajo de Diploma de ICTB- } \\
\text { UH. }\end{array}$ \\
\hline & & $\begin{array}{l}\text { Identificaciónde bibliotecarios cu ba nos re le van- } \\
\text { tes du ran te los años de la dé ca da del } 30 \text { a la del } 50 .\end{array}$ & $\begin{array}{l}\text { Análisis de índices de revistas } \\
\text { bibliotecológicas. }\end{array}$ & Tra ba jos de gra do de la ENTB. \\
\hline \multirow[t]{4}{*}{$\begin{array}{l}\text { Organizaciones de biblioteca- } \\
\text { rios. }\end{array}$} & M & $\begin{array}{l}\text { Identificación de organizaciones cubanas de bi- } \\
\text { bliotecarios du ran te el perío do an tes se ña la do. }\end{array}$ & Ibid. & Ibid. \\
\hline & & $\begin{array}{l}\text { Estructura generalizada de prioridades para el } \\
\text { completamiento del fondobibliotecario. }\end{array}$ & Selección y adquisición. & Tareas de tema de PPS 1981- 85. \\
\hline & & $\begin{array}{l}\text { Nor mas so bre la for ma ción y el com ple ta mien to } \\
\text { del fondo bibliotecario. }\end{array}$ & Ibid. & Ibid. \\
\hline & & $\begin{array}{l}\text { Lineamientosyrecomendacionesparamodificar } \\
\text { políticas de completamiento del fondo bibliote- } \\
\text { cario en el sistema de bibliotecas públicas y en } \\
\text { bibliotecasparticulares. }\end{array}$ & Eva lua ción de fon dos. & $\begin{array}{l}\text { Tarea de tema de PPS 1981-85; } \\
\text { tema de PPS 1986-90. }\end{array}$ \\
\hline $\begin{array}{l}\text { Dis tri bu ción de fon dos se gún ti- } \\
\text { pos de bibliotecas. }\end{array}$ & $\mathrm{O}$ & & & \\
\hline Conservación. & $\mathrm{m}$ & $\begin{array}{l}\text { Tra ta mien tos de aplica ción in me dia ta para la con- } \\
\text { servación del fondobibliotecario valioso. }\end{array}$ & $\begin{array}{l}\text { Conservación del Patrimonio } \\
\text { Bibliográfico. }\end{array}$ & Tarea de tema de PPS 1981-85. \\
\hline \multicolumn{5}{|c|}{ Métodos para el estudio y eva lua ción de: } \\
\hline \multirow[t]{2}{*}{-Composición delfon do. } & M & $\begin{array}{l}\text { Método para evaluar el fondo bibliotecario con } \\
\text { su mo vi mien to (prés ta mos) y la de man da de los } \\
\text { lectores no satisfecha. Algoritmo para definir } \\
\text { priori da des en la ad qui sición, el descarte y la ele- } \\
\text { vación del préstamoen distintaste máticas. }\end{array}$ & Evalua ción de fon dos. & $\begin{array}{l}\text { Tarea de tema de PPS 1981-85. } \\
\text { Tema de PP 1986-90. }\end{array}$ \\
\hline & & $\begin{array}{l}\text { Mé to do para iden ti fi car los com po nen tes del fon- } \\
\text { do bi blio te cario que tie nen prés ta mos sig nifica ti } \\
\text { vos. Mé to do para eva luar la de man da de los lec- } \\
\text { tores, no sa tisfechos. }\end{array}$ & Eva lua ción de la de si de ra ta. & $\begin{array}{l}\text { Tarea de diplomaICTB-UH. } \\
\text { Tarea de tema de PPS 1981-85. } \\
\text { Tema de PP 1986-90. }\end{array}$ \\
\hline -Organización. & $\mathrm{O}$ & & & \\
\hline -Conservación & M & $\begin{array}{l}\text { Método para el análisis de los factores físicos, } \\
\text { químicos y biológicos que afectan la conserva- } \\
\text { cióndel fon do bi bliotecario. }\end{array}$ & $\begin{array}{l}\text { Conservación de Patrimonio } \\
\text { Bibliográfico. }\end{array}$ & Tarea de tema de PPS 1981-85 \\
\hline -Con trol del fon do. & $\mathrm{O}$ & & & \\
\hline
\end{tabular}

* $\mathrm{M}=$ mayor grado $\mathrm{m}=$ menor grado $\mathrm{O}=$ no cubrimiento 
Fundamentos teóricos y metodológicos... / 15

\begin{tabular}{|c|c|c|c|c|}
\hline CONTENIDO & $\begin{array}{l}\text { GRA- } \\
\mathrm{DO}^{*} \\
\end{array}$ & $\begin{array}{l}\text { DESCRIPCION DE } \\
\text { RESULTADOS } \\
\end{array}$ & $\begin{array}{c}\text { TRABAJO DE } \\
\text { INVESTIGACION }\end{array}$ & $\begin{array}{c}\text { TIPO DE } \\
\text { INVESTIGACION }\end{array}$ \\
\hline $\begin{array}{l}\text {-Sistema de abastecimiento a } \\
\text { las bibliotecas. }\end{array}$ & $\mathrm{m}$ & $\begin{array}{l}\text { Com por ta mien to en las sa tis fac ción de la deman- } \\
d a \text { de títuloscomercializados en el país. }\end{array}$ & & Trabajo de grado. \\
\hline $\begin{array}{l}\text { - Selección } \\
\text {-Adquisición. }\end{array}$ & M & $\begin{array}{l}\text { Ma nual de proce di mien tos para la se lec ción y ad- } \\
\text { qui si ción de do cu men tos a in cor po rar alfon do bi- } \\
\text { bliotecario. }\end{array}$ & Selección y adquisición. & Ta rea de tema de PPS $1981-85$. \\
\hline -Canje. & $\mathrm{m}$ & $\begin{array}{l}\text { Eva lua ción del can je de la BNJM con las bi blio- } \\
\text { te cas naciona les de países so cia lis tas como vía de } \\
\text { completamiento del fondo bibliotecario. }\end{array}$ & Ibid. & Ibid. \\
\hline -Donativos. & $\mathrm{O}$ & & & \\
\hline —Depósito legal. & M & $\begin{array}{l}\text { Proyectode modificación deldecre to } 3387 \text { so bre } \\
\text { la entrega de ejemplares obligatorios para el } \\
\text { completamiento del fondo bibliotecario. }\end{array}$ & Ibid. & Ibid. \\
\hline -Descarte. & M & $\begin{array}{l}\text { Manual de procedimientos para el descarte del } \\
\text { fondobibliotecario. }\end{array}$ & Ibid. & Ibid. \\
\hline $\begin{array}{l}\text {-Tipología de documen tos que } \\
\text { integranelfondobibliotecario. }\end{array}$ & $\mathrm{O}$ & & & \\
\hline -Procesamientofísico. & $\mathrm{O}$ & & & \\
\hline -Almacenamiento. & M & $\begin{array}{l}\text { Nor ma so bre la or de na ción delfondobiblioteca- } \\
\text { rio }\end{array}$ & $\begin{array}{l}\text { Conservación del Patrimonio } \\
\text { Bibliográfico. }\end{array}$ & Ta rea de tema de PPS 1981- 85. \\
\hline $\begin{array}{l}\text { - Regulaciones para el uso del } \\
\text { fondo. }\end{array}$ & M & $\begin{array}{l}\text { An te pro yec to del re gla men to para el uso delfon- } \\
\text { dobibliotecario. }\end{array}$ & Ibid. & Ibid. \\
\hline \multicolumn{5}{|c|}{ SISTEMAS DE CATALOGOS } \\
\hline Descripción (catalogación). & $\mathrm{O}$ & & & \\
\hline \multirow[t]{2}{*}{$\begin{array}{l}\text { Sistematización (clasificación, } \\
\text { indización). }\end{array}$} & M & $\begin{array}{l}\text { Traducción, adaptación e instrucciones para la } \\
\text { apli ca ción en Cuba de la CBB- URSS alfondo de } \\
\text { Marxis mo-Leninismo. In clu ye tabla que re lacio } \\
\text { na los ín di ces de ese sis te ma con los que ac tual- } \\
\text { menteempleanlasbibliotecaspúblicascubanas. }\end{array}$ & $\begin{array}{l}\text { Aplicación experimental de la } \\
\text { CBB-URSS. }\end{array}$ & Ta rea de tema de PPS 1981- 85 . \\
\hline & & $\begin{array}{l}\text { Ibid. para las ciencias sociales y las Humanida- } \\
\text { des. }\end{array}$ & $\begin{array}{l}\text { Adaptación de la CBB para su } \\
\text { aplicación en Cuba. }\end{array}$ & Trabajode as piran tura 1986- 90. \\
\hline $\begin{array}{l}\text { Prin ci pios y mé to dos de for ma- } \\
\text { ción de catálogos. }\end{array}$ & $\mathrm{O}$ & & & \\
\hline $\begin{array}{l}\text { Distin tos ti pos de ca tálogosque } \\
\text { in tegranel sis te made búsque da } \\
\text { informativa de las bibliotecas } \\
\text { (manuales, automatizadas). }\end{array}$ & $\mathrm{m}$ & $\begin{array}{l}\text { Sistemas automatizados para la compilación de } \\
\text { bibliografías ycatálogoscolectivosprovinciales. }\end{array}$ & $\begin{array}{l}\text { Automatización de procesos } \\
\text { bibliotecarios. }\end{array}$ & Ta rea de tema de PPS 1981- 85 . \\
\hline \multicolumn{5}{|c|}{ TRABAJOS CON LOS LECTORES } \\
\hline $\begin{array}{l}\text { Estudio sobre el empleo de los } \\
\text { fondos por los lec to res. }\end{array}$ & M & $\begin{array}{l}\text { Recomendaciones para mejorar la composición } \\
\text { de los lectores en las bibliotecas públicas, de } \\
\text { acuerdo con la composición de la población que } \\
\text { atienden esas instituciones. }\end{array}$ & Dinámica de la lectura. & $\begin{array}{l}\text { Ta rea de tema de PPS 1981- } 85 . \\
\text { Tema de PP 1986- } 90 .\end{array}$ \\
\hline $\begin{array}{l}\text { La lectura según grupos socia- } \\
\text { les. }\end{array}$ & M & $\begin{array}{l}\text { Per fi les de lademanda delectores de dis tin tos ti- } \\
\text { pos, segúncaracterísticas sociodemográficas. }\end{array}$ & $\begin{array}{l}\text { Categorías y perfiles de lecto- } \\
\text { res. }\end{array}$ & Ibid. \\
\hline \multirow[t]{2}{*}{ Ti pos de lec tu ra } & $\mathrm{m}$ & Análisis de los hábitos de lectura en Cuba. & & Trabajo de diplomaICTB-UH. \\
\hline & & Los há bi tos de lectura de nove las en Cuba. & & Ibid. \\
\hline Ti pos de lec to res. & M & $\begin{array}{l}\text { Ti po lo gía delectoresen las bi blio te cas públicas, } \\
\text { se gún: ac ti tud ante la lectura; característicasso- } \\
\text { ciodemográficas; intereses temáticos; relevan- } \\
\text { cia; ob je ti vos de lec tura. }\end{array}$ & $\begin{array}{l}\text { Categorías y perfiles de lecto- } \\
\text { res. }\end{array}$ & Ibid. \\
\hline
\end{tabular}




\begin{tabular}{|c|c|c|c|c|}
\hline CONTENIDO & $\begin{array}{l}\text { GRA- } \\
\text { DO* }^{*}\end{array}$ & $\begin{array}{l}\text { DESCRIPCION DE } \\
\text { RESULTADOS }\end{array}$ & $\begin{array}{c}\text { TRABAJO DE } \\
\text { INVESTIGACION }\end{array}$ & $\begin{array}{c}\text { TIPO DE } \\
\text { INVESTIGACION }\end{array}$ \\
\hline & & $\begin{array}{l}\text { Identificacióndelosestudiantesuniversitariosen } \\
\text { ge ne ral y de los es tu dian tes de Pe da go gía en ge- } \\
\text { ne ral como lectores más re le van tes de las bi blio- } \\
\text { tecas pú bli cas. Los pri me ros se gún su peso en la } \\
\text { solicitud de préstamos; los segundos, además, } \\
\text { por la diversidad de temáticas consultadas. En } \\
\text { am bos ca sos la can ti dad de prés ta mospercápita } \\
\text { es in fe rior al de otros ti pos de lec to res. }\end{array}$ & Ibid. & $\begin{array}{l}\text { Tarea de tema de PPS 1981-85. } \\
\text { Tema de PP 1986-90. }\end{array}$ \\
\hline & & $\begin{array}{l}\text { Ti po lo gía delectores en bibliotecas de Casas de } \\
\text { Cultura y de Centros de educación superior. }\end{array}$ & $\begin{array}{l}\text { Usuarios de distintos tipos de } \\
\text { bibliotecas. }\end{array}$ & Tema de PR 1986-90. \\
\hline \multirow[t]{4}{*}{$\begin{array}{l}\text { Principios y métodos de propa- } \\
\text { gan da dellibro. }\end{array}$} & M & $\begin{array}{l}\text { Fun da men tos me to do ló gi cos para losestudios de } \\
\text { lectores en las bibliotecas públicascubanas. }\end{array}$ & Dinámica de la lectura. & $\begin{array}{l}\text { Ta rea de tema de PPS } 1981-85, \\
\text { Tema de PP 1986-90. }\end{array}$ \\
\hline & & & $\begin{array}{l}\text { Categorías y Perfiles de lecto- } \\
\text { res. }\end{array}$ & Ibid. \\
\hline & & $\begin{array}{l}\text { Precisión del concepto de circulación del fondo } \\
\text { biblio te cario y de los concep tos delectores rea les } \\
\text { y po ten cia les de las bibliotecas. }\end{array}$ & $\begin{array}{l}\text { Modelación matemática apli- } \\
\text { ca da a la ges tión de las bi blio- } \\
\text { tecas públicas. }\end{array}$ & Trabajode aspiran tura 1986-90. \\
\hline & & $\begin{array}{l}\text { Necesa ria vinculación del tra ba jocon gru pos de } \\
\text { lectores y del trabajo individual con ellos, para } \\
\text { una pro pa gan da más efec ti va del libro. }\end{array}$ & $\begin{array}{l}\text { Mé to dos de tra ba jo con los lec- } \\
\text { tores }\end{array}$ & Tema de PR 1986-90. \\
\hline \multirow[t]{5}{*}{ Orien ta ción de la lec tu ra. } & M & $\begin{array}{l}\text { Par tes delfondobibliotecario que de ben ser prio- } \\
\text { rizados en la orientaciónde la lectura. }\end{array}$ & Eva lua ción de fon dos. & $\begin{array}{l}\text { Tarea de tema de PPS 1981-85. } \\
\text { Tema de PP 1986-90. }\end{array}$ \\
\hline & & $\begin{array}{l}\text { Tipos de lec to res ha cia los que se debe di ri gir la } \\
\text { orientaciónde la lectura. }\end{array}$ & $\begin{array}{l}\text { Dinámica de la lectura. } \\
\text { Categorías y perfiles de lecto- } \\
\text { res. }\end{array}$ & Ibid. \\
\hline & & $\begin{array}{l}\text { Necesidad de dirigir la orientación de la lectura } \\
\text { hacia la elevación de la cantidad de préstamos } \\
\text { por lector. }\end{array}$ & $\begin{array}{l}\text { Evalua ción de fon dos. } \\
\text { Dinámica de la lectura. }\end{array}$ & $\begin{array}{l}\text { Ibid. } \\
\text { Ibid. }\end{array}$ \\
\hline & & $\begin{array}{l}\text { Tipologíade activida desora les de orien ta ción de } \\
\text { lalectura. }\end{array}$ & $\begin{array}{l}\text { Método de tra ba jo con los lec- } \\
\text { tores. }\end{array}$ & Tema de PR 1986-90. \\
\hline & & $\begin{array}{l}\text { Niveles de efectividad de las actividades orales } \\
\text { de orien tación de la lec tura, se gún mé to dos, for- } \\
\text { mas y ti pos de lectores. }\end{array}$ & Ibid. & Ibid. \\
\hline $\begin{array}{l}\text { Información biblioteco-biblio- } \\
\text { gráfica. }\end{array}$ & $\mathrm{O}$ & & & \\
\hline $\begin{array}{l}\text { Servicios a lectores en distintos } \\
\text { tiposdebibliotecas. }\end{array}$ & $\mathrm{O}$ & & & \\
\hline $\begin{array}{l}\text { Préstamos: internos; } \\
\text { externos; }\end{array}$ & $\begin{array}{l}\text { M } \\
\text { M }\end{array}$ & $\begin{array}{l}\text { Base de datos para el análisis de los trabajos de } \\
\text { Evaluación de fondos, Dinámica de la lectura, } \\
\text { Ca te go rías y perfiles de lectores. }\end{array}$ & & \\
\hline Interbibliotecarios. & $\mathrm{O}$ & & & \\
\hline En extensión. & $\mathrm{O}$ & & & \\
\hline $\begin{array}{l}\text { Entrega de reproducciones de } \\
\text { documentos. }\end{array}$ & $\mathrm{O}$ & & & \\
\hline $\begin{array}{l}\text { Orientación sobre el uso de las } \\
\text { bibliotecas. }\end{array}$ & $\mathrm{O}$ & & & \\
\hline Trabajodereferencia. & $\mathrm{O}$ & & & \\
\hline
\end{tabular}

* $\mathrm{M}=$ mayor grado $\mathrm{m}=$ menor grado $\mathrm{O}=$ no cubrimiento 


\begin{tabular}{|c|c|c|c|c|}
\hline CONTENIDO & $\begin{array}{l}\text { GRA- } \\
\mathrm{DO}^{*}\end{array}$ & $\begin{array}{l}\text { DESCRIPCION DE } \\
\text { RESULTADOS } \\
\end{array}$ & $\begin{array}{c}\text { TRABAJO DE } \\
\text { INVESTIGACION }\end{array}$ & $\begin{array}{c}\text { TIPO DE } \\
\text { INVESTIGACION }\end{array}$ \\
\hline \multicolumn{5}{|c|}{ ORGANIZACION DE BIBLIOTECAS } \\
\hline Direc ción de biblio te cas. & M & $\begin{array}{l}\text { De fi ni ción de los ti pos de fun cio nes que in te gran } \\
\text { el sis te ma de di rec ción de lasbibliotecas: sus re- } \\
\text { laciones y contenido. }\end{array}$ & $\begin{array}{l}\text { Componentes del sistema de } \\
\text { dirección de las bibliotecas. }\end{array}$ & Tema de PR 1986- 90. \\
\hline Planificación. & $\mathrm{m}$ & De finición de tareas. & Ibid. & Ibid. \\
\hline Organización. & $\mathrm{m}$ & Ibid. & Ibid. & Ibid. \\
\hline Control & $\mathrm{m}$ & Ibid. & Ibid. & Ibid. \\
\hline Normación. & $\mathrm{m}$ & $\begin{array}{l}\text { De fi ni ción pre li mi nar de los hom bres hora re que } \\
\text { ri dos por las fun cio nes de ges tión, me to do ló gi cas } \\
\text { y de in ves ti ga ción del sis te ma de di rec ción de las } \\
\text { bibliotecaspúblicascubanas. }\end{array}$ & Ibid. & Ibid. \\
\hline $\begin{array}{l}\text { Estructura de distintos tipos de } \\
\text { bibliotecas. }\end{array}$ & $\mathrm{O}$ & & & \\
\hline \multirow[t]{5}{*}{$\begin{array}{l}\text { Técnica, tecnología y equipa- } \\
\text { mien to de las biblio te cas. }\end{array}$} & $\mathrm{m}$ & $\begin{array}{l}\text { Sistema automatizado para el procesamiento de } \\
\text { los da tos uti li za dosen los es tu dios de lec to res. }\end{array}$ & Dinámica de la lectura. & $\begin{array}{l}\text { Ta rea de tema de PPS 1981- } 85 \text {, } \\
\text { Tema de PP 1986-90 Tra ba jo de } \\
\text { diploma ICTB-UH. }\end{array}$ \\
\hline & & $\begin{array}{l}\text { Sistema automatizado para los estudios de eva- } \\
\text { luación de fondos bibliotecarios. }\end{array}$ & Evaluación de fondos. & $\begin{array}{l}\text { Ta rea de tema de PPS 1981- } 85 . \\
\text { Tema de PP 1986- } 90 .\end{array}$ \\
\hline & & $\begin{array}{l}\text { Sistema automatizado para los estudios de inci- } \\
\text { dencia de la capacitación. }\end{array}$ & Incidencia de la capacitación. & Ibid. \\
\hline & & $\begin{array}{l}\text { Sistema automatizado para el control y evalua- } \\
\text { ción de la de mandade los lectoresnosatisfe chos. }\end{array}$ & & Trabajo de diplomaICTB-UH. \\
\hline & & $\begin{array}{l}\text { Sistemas automatizados para la compilación de } \\
\text { bibliografíasycatálogoscolectivosprovinciales. }\end{array}$ & $\begin{array}{l}\text { Automatización de procesos } \\
\text { bibliotecarios. }\end{array}$ & Ta rea de tema de PPS 1981- 85. \\
\hline Edificiosparabibliotecas. & $\mathrm{O}$ & & & \\
\hline $\begin{array}{l}\text { Eje cu ción prác tica de las fun cio } \\
\text { nes de las bibliotecas. }\end{array}$ & $\mathrm{m}$ & Definición de tareas. & $\begin{array}{l}\text { Componentes del sistema de } \\
\text { dirección de bibliotecas. }\end{array}$ & Tema de PR 1986- 90. \\
\hline \multirow[t]{6}{*}{$\begin{array}{l}\text { Eva lua ción y re gu la ción del trat } \\
\text { bajo de las bibliotecas. }\end{array}$} & M & Definición de tareas. & Ibid. & Ibid. \\
\hline & & $\begin{array}{l}\text { Lineamientosyrecomendacionesparamodificar } \\
\text { políticas de completamiento del fondo bibliote- } \\
\text { carioen el sis te made biblio te cas públicas yen bi } \\
\text { bliotecas particulares. }\end{array}$ & Evaluación de fondos. & $\begin{array}{l}\text { Ta rea de tema de PPS 1981- } 85 . \\
\text { Tema de PP 1986- } 90 .\end{array}$ \\
\hline & & $\begin{array}{l}\text { Recomendaciones para mejorar la composición } \\
\text { de los lectores en las bibliotecas públicas, de } \\
\text { acuer do con la po bla ción que atien den esas ins ti- } \\
\text { tuciones. }\end{array}$ & Dinámica de la lectura. & Ibid. \\
\hline & & $\begin{array}{l}\text { Par tes del fon do bi blio te ca rio que de ben ser prio- } \\
\text { rizados en la orien ta ción de la lec tu ra. }\end{array}$ & Evaluación de fondos. & Ibid. \\
\hline & & $\begin{array}{l}\text { Ti pos de lec to res ha cia los que se debe di ri gir la } \\
\text { orien ta ción de la lec tu ra. }\end{array}$ & \begin{tabular}{|l|} 
Dinámica de la lectura. \\
Categorías y perfiles de lecto- \\
res.
\end{tabular} & Ibid. \\
\hline & & $\begin{array}{l}\text { Necesidad de dirigir la orientación de la lectura } \\
\text { hacia la elevación de la cantidad de préstamos } \\
\text { por lector. }\end{array}$ & $\begin{array}{l}\text { Evaluación de fondos. } \\
\text { Dinámica de la lectura. }\end{array}$ & $\begin{array}{l}\text { Ibid. } \\
\text { Ibid. }\end{array}$ \\
\hline \multirow[t]{3}{*}{ Normalización. } & $\mathrm{m}$ & $\begin{array}{l}\text { Norma sobre la formación y el completamiento } \\
\text { delfondobibliotecario. }\end{array}$ & Selección y adquisición. & Ta rea de tema de PPS $1981-85$. \\
\hline & & $\begin{array}{l}\text { Nor ma so bre la or de na ción del fon do bi blio te ca- } \\
\text { rio. }\end{array}$ & $\begin{array}{l}\text { Conservación del Patrimonio } \\
\text { bibliográfico. }\end{array}$ & Ibid. \\
\hline & & $\begin{array}{l}\text { Nor ma so bre la ti po logía de lec to res en las bi blio- } \\
\text { tecas públicas según características sociodemo- } \\
\text { gráficas. }\end{array}$ & $\begin{array}{l}\text { Categorías y perfiles de lecto- } \\
\text { res. }\end{array}$ & $\begin{array}{l}\text { Ta rea de tema de PPS 1981- } 85 . \\
\text { Tema de PP 1986- } 90 .\end{array}$ \\
\hline
\end{tabular}




\begin{tabular}{|c|c|c|c|c|}
\hline CONTENIDO & $\begin{array}{l}\text { GRA- } \\
\mathrm{DO}^{*}\end{array}$ & $\begin{array}{l}\text { DESCRIPCION DE } \\
\text { RESULTADOS }\end{array}$ & $\begin{array}{c}\text { TRABAJO DE } \\
\text { INVESTIGACION }\end{array}$ & $\begin{array}{c}\text { TIPO DE } \\
\text { INVESTIGACION }\end{array}$ \\
\hline Legislación. & $\mathrm{m}$ & $\begin{array}{l}\text { Pro yec to de mo dificación de la le gis la ción so bre } \\
\text { el ejemplar obligatorio para el completamiento } \\
\text { delfondobibliotecario. }\end{array}$ & Selección y adquisición. & Tarea de tema de PPS 1981-85. \\
\hline \multicolumn{5}{|l|}{ Personal de las bibliotecas: } \\
\hline Calificación. & $\mathrm{O}$ & & & \\
\hline Desarrollo & M & $\begin{array}{l}\text { Diseño de cursos de ac tua li za ción de bi blio teca } \\
\text { rioss }\end{array}$ & In ci den cia de la ca pa ci ta ción. & $\begin{array}{l}\text { Tarea de tema de PPS 1981-85. } \\
\text { Tema de PP 1986-90. }\end{array}$ \\
\hline Remuneración. & $\mathrm{O}$ & & & \\
\hline Alcance de las bibliotecas. & $\mathrm{m}$ & Mé to do para me dir el al can ce de las bi blio te cas. & $\begin{array}{l}\text { Modelación matemática apli- } \\
\text { ca do a la ges tión de las bi blio- } \\
\text { tecaspúblicas. }\end{array}$ & Trabajode as pirantura 1981-90. \\
\hline Costos. & $\mathrm{m}$ & $\begin{array}{l}\text { Indicadores para el análisis de los costos de bi- } \\
\text { bliotecas provinciales y municipales: por fun- } \\
\text { ción, por produc to de cada fun ción. }\end{array}$ & $\begin{array}{l}\text { Factores económicos del tra- } \\
\text { bajodelas bibliotecas. }\end{array}$ & Tema de PR 1986-90. \\
\hline
\end{tabular}

ANEXO 2

Cuantificación de los resultados de las investigaciones según su relación con las categorías principales de la Bibliotecología.

\begin{tabular}{||l|c|}
\hline \multicolumn{1}{|c|}{ Categorías } & $\begin{array}{c}\% \text { de resul- } \\
\text { tados rela- } \\
\text { cionados }\end{array}$ \\
\hline Bibliotecario & $10.13 \%$ \\
\hline Fondo bibliotecario & $21.52 \%$ \\
\hline Préstamos & $7.59 \%$ \\
\hline Biblioteca & $16.45 \%$ \\
\hline Alcance social de las bibliotecas & $2.53 \%$ \\
\hline Comunicación & $1.27 \%$ \\
\hline Libro & $1.27 \%$ \\
\hline Lectura & $3.80 \%$ \\
\hline Lectores & $18.99 \%$ \\
\hline Demanda de los lectores & $7.59 \%$ \\
\hline Orientación de la lectura & $8.86 \%$ \\
\hline & $100.00 \%$ \\
\hline
\end{tabular}




\section{ANEXO 3}

Cuantificación de los resultados de las investigaciones según su relación con los epígrafes que reflejan el contenido de las disciplinas que integran la Bibliotecología.

\begin{tabular}{|l|c|c|c||}
\hline \multicolumn{1}{|c|}{ Disciplinas } & $\begin{array}{c}\text { Epígrafes que } \\
\text { reflejan el con- } \\
\text { tenido }\end{array}$ & Resultados & $\begin{array}{c}\text { Promedio de } \\
\text { resultados por } \\
\text { epígrafe }\end{array}$ \\
\hline Bibliotecología general & 12 & 23 & 1.92 \\
\hline Formación de fondos & 19 & 16 & 0.84 \\
\hline Sistema de catálogos & 4 & 3 & 0.75 \\
\hline Trabajo con los lectores & 15 & 16 & 1.07 \\
\hline Organización de bibliotecas & 17 & 24 & 1.41 \\
\hline Totales & 67 & 82 & 1.22 \\
\hline
\end{tabular}

\section{ANEXO 4}

Cobertura de los epígrafes que representan los contenidos de las disciplinas que integran la estructura de la Bibliotecología

\begin{tabular}{|l|c|c|c|c||}
\hline \multicolumn{1}{|c|}{ Disciplinas } & $\begin{array}{c}\text { Epígrafes } \\
\text { que } \\
\text { representan } \\
\text { el } \\
\text { contenido }\end{array}$ & $\begin{array}{c}\text { Cubiertos en } \\
\text { mayor grado }\end{array}$ & $\begin{array}{c}\text { Cubiertos en } \\
\text { menor grado }\end{array}$ & No cubiertos \\
\hline Bibliotecología general & 12 & 7 & 4 & 1 \\
\hline Formación de fondos & 19 & 10 & 3 & 6 \\
\hline Sistema de catálogos & 4 & 1 & 1 & 2 \\
\hline Trabajo con los lectores & 15 & 7 & 1 & 7 \\
\hline Organización de bibliotecas & 17 & 3 & 10 & 4 \\
\hline Totales & 67 & 28 & 19 & 20 \\
\hline
\end{tabular}




\section{ANEXO 5}

Epígrafes del contenido de las disciplinas de la Bibliotecología cubiertos en menor grado o no cubiertos por los resultados de las investigaciones

\begin{tabular}{|c|c|c|}
\hline Disciplina & Epígrafes cubiertos en menor grado & Epígrafes no cubiertos \\
\hline Bibliotecología general. & $\begin{array}{l}\text { Papel social de las bibliotecas como instituciones } \\
\text { ideológicas e informativas; tipología de las bibliote- } \\
\text { cas; bibliotecas para distintos tipos de lectores; rela- } \\
\text { ciones de la Bibliotecología con otras disciplinas. }\end{array}$ & Instituciones para la formación de bibliotecarios. \\
\hline Formación de fondos. & $\begin{array}{l}\text { Con serva ción del fon do; sis te ma de abas te ci mien to a } \\
\text { las bibliotecas; canje. }\end{array}$ & $\begin{array}{l}\text { Dis tri bu ción de fon dos se gún ti pos de bi blio te cas; or- } \\
\text { ganización y control del fondo bibliotecario; do nati- } \\
\text { vos; tipología de documentos; procesamiento físico. }\end{array}$ \\
\hline Sistema de catálogos. & $\begin{array}{l}\text { Dis tin tos ti pos de ca tálo gos que in te gran el sis te ma de } \\
\text { búsqueda informativa (manuales, automatizados). }\end{array}$ & $\begin{array}{l}\text { Descripción (catalogación); principios y métodos de } \\
\text { formación de catálogos. }\end{array}$ \\
\hline Trabajo con los lectores. & Tipos y hábitos de lectura. & $\begin{array}{l}\text { Información biblioteco-bibliográfica; servicios a lec- } \\
\text { tores en dis tin tos tipos de bi blio tecas; prés ta mosin ter- } \\
\text { bibliotecarios; préstamos en extensión; servicios de } \\
\text { re produc ción de documen tos; orien ta ción so bre el uso } \\
\text { de las bibliotecas; trabajo de referencia. }\end{array}$ \\
\hline $\begin{array}{l}\text { Organización de bibliote- } \\
\text { cas. }\end{array}$ & 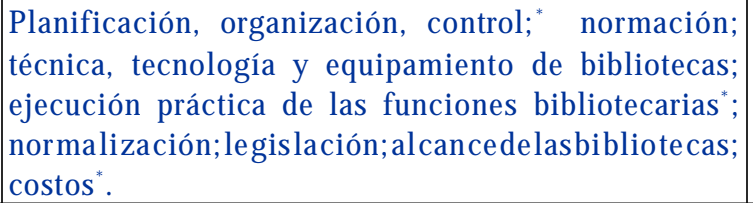 & $\begin{array}{l}\text { Es truc turas de dis tin tos ti pos de bibliotecas; edificios; } \\
\text { calificación del personal; remuneración. }\end{array}$ \\
\hline
\end{tabular}

* son objeto de investigaciones corrientes con resultados progra ma dos para fi nes del quin que nio 1986-1990.

\section{ANEXO 6}

Cuantificación de los resultados de utilidad común a más de una disciplina

\begin{tabular}{|c|c|c|c|}
\hline Disciplinas con resultados comunes & \multicolumn{3}{|c|}{$\begin{array}{c}\% \text { del total de resultados co- } \\
\text { munes }\end{array}$} \\
\hline Formación de fondos - Bibliotecología general & \multirow{8}{*}{$27 \%$} & $9 \%$ & \multirow{8}{*}{$50 \%$} \\
\hline Trabajo con los lectores-Bibliotecología general & & $9 \%$ & \\
\hline Organización de bibliotecas-Bibliotecología ge neral & & $9 \%$ & \\
\hline Organización de bibliotecas -Formación de fondos & & $24 \%$ & \\
\hline Organización de bibliotecas - Sistema de catálogos & & $2 \%$ & \\
\hline Organización de bibliotecas - Trabajo con los lectores & & $15 \%$ & \\
\hline \multirow[t]{2}{*}{ Formación de fondos - Trabajo con los lectores } & & $32 \%$ & \\
\hline & & $100 \%$ & \\
\hline
\end{tabular}

